\title{
Hipertextualidad y "Ficción del Archivo" en El negrero de Lino Novás Calvo*
}

\author{
Jesús Gómez de Tejada \\ Universidad de Sevilla \\ joomezdetejada@us.es \\ https://dx.doi.org/10.12795/futhark.2014.i9.05
}

Resumen: El negrero. Vida novelada de Pedro Blanco Fernández de Trava, la biografía del histórico tratante español, aparecida en 1933 en EspasaCalpe, única "novela" de Lino Novás Calvo, condensa en su seno de forma temprana, inaugural, novedosa o germinal algunas de las más importantes tendencias de la historia literaria hispanoamericana del siglo $X X:$ la narrativa antiesclavista, la corriente negrista afrocubana, la fusión de la historia y la ficción, la diáspora africana, lo real maravilloso americano y el realismo mágico, la novela histórica moderna, la novela de la dictadura o la proliferación de recursos metaliterarios e intertextuales; todas ellas líneas de creación confirmadas por la producción posterior de los más conspicuos escritores de Hispanoamérica. El análisis propuesto, que parte de su consideración como biografía moderna o literaria nacida como escritura de encargo en la colección "Vidas extraordinarias", una de las series biográficas promovidas por José Ortega y Gasset, se centra en la justifica-

\footnotetext{
- Este artículo pretende ser un diálogo abierto con dos obras anteriores, que le sirven de fuente de inspiración y documentación: el libro Mito y Archivo de Roberto González Echevarría y el artículo "Pedro Blanco, el negrero: ¿novela o biografía novelada?" de Roberto Véguez.

Este estudio ha sido posible gracias a una beca de investigación asociada al Proyecto de Excelencia de la Junta de Andalucía "Migraciones intelectuales: Escritores hispanoamericanos en España (1914-1936)" dirigido por la Dra. Carmen de Mora Valcárcel.
}

Futhark 9 (2014)

Recibido 28/05/2014

ISSN $1886-9300$

Aceptado 04/10/2014 
ción de su posible consideración como "ficción del Archivo" a partir del revonocimiento en ella de las premisas establecidas por Roberto González Echeverría en su definición de tal concepto.

Palabras claves: Lino Novás Calvo, Pedro Blanco, el negrero, Mito y Archivo, biografía moderna, narrativa cubana, Roberto González Echevarría

Abstract: El negrero. Vida novelada de Pedro Blanco Fernández de Trava, the biography of the historical Spanish slave trader, published in 1933 by Espasa Calpe, the only Lino Novás Calvo's "novel", is an soon and original precedent of some of the most important Hispanic-American literary history's trends in twentieth century: anti-slavery narrative, Afro-Cuban movement, the fusion between history and fiction, African Diaspora, the American Marvelous Real and Magical Realism, the New Historical Novel, the Dictator Novel or the abundance of metaliterary and intertextual resources; all of them presents in the later production of the most famous Hispanic-American authors. This analysis considers El negrero as a Modem or Literary Biography written for the collection "Vidas extraordinarias", one of the biographical series promoted by José Ortega y Gasset. From this statement it reflects on its possible consideration as "archival fiction" justified by the recognition in the text of the characteristics used by Roberto González Echevarria to define this concept.

Words Key: Lino Novás Calvo, Pedro Blanco, el negrero, Modern Biography, Myth and Archive, Cuban narrative, Roberto González Echevamía

En 1933 el autor gallego-cubano Lino Novás Calvo publicó en Madrid El negrero. Vida novelada de Pedro Blanco Fernández de Trava. Novás había regresado a España apenas dos años antes como corresponsal de la publicación habanera Orbe tras una estancia en Cuba de diez años. Iniciada en importantes revistas de la isla, su formación como escritor se consolidará en su segundo periodo español (1931-1939), a través de numerosas colaboraciones en publicaciones periódicas diversas, que le convirtieron en el autor hispanoamericano con más presencia en Revista de Occidente 1 . Dentro de los círculos letrados peninsulares recibió la propuesta de uno de los miembros de la generación de prosistas del 27, Antonio Marichalar, afín a José Ortega y Gasset, de participar en la segunda de las colecciones biográficas

\footnotetext{
${ }^{1}$ López Campillo 72.
} 
propulsadas por este último a través de la editorial Espasa Calpe, concretamente la serie "Vidas extraordinarias" donde apareció la obra ${ }^{2}$.

La doble experiencia geográfica y cultural de Novás y la bipolaridad de las circunstancias que rodearon el origen de su obra condicionan el estudio de El negrero a una duplicidad focal que aconseja tener en cuenta por un lado, la corriente genérica en la que surge como escritura de encargo, es decir, la biografía moderna de plena actualidad en España e Hispanoamérica desde el año 1928 y hasta finales de los años 40; y tras esto, aquella otra en la que queda inserta a través de la creación de la atmósfera esclavista en que cobra vida el sujeto histórico biografiado y el uso de una serie de recursos que ponen el texto en relación con la moda negrista europea de principios de siglo, y más específicamente con su singular concreción en la poesía y narrativa afrocubanas de la época.

La profundización en las condiciones literarias y sociales que rodearon la aparición de El negrero, que incluyen su encargo, redacción y publicación, contribuye a comprender y definir mejor el género al que preferentemente pertenece: el biografismo moderno, en cuyo seno la hibridez que lo caracteriza cobra un sentido específico. La inclusión en esta tendencia supone tener en cuenta todo un aparato teórico y crítico desarrollado en el periodo de entreguerras del siglo XX $X^{3}$. La

2 La primera sería "Vidas españolas del siglo XIX", llamada "Vidas españolas e hispanoamericanas del siglo XIX" a partir del número 11 de la colección, que se inició en 1929 y se prolongó durante la guerra civil. Por su parte, "Vidas extraordinarias" redujo su periodo de aparición a los años transcurridos entre 1932 y 1935.

${ }^{3}$ Hay tres estudios minuciosos sobre esta explosión biográfica en España: Vidas oblicuas: Aspectos teóricos de la nueva biografia en España (1928-1936) de Enrique Serrano Asenjo (Zaragoza: Prensas Universitarias de Zaragoza, 2002); Plutarco de Moda. La biografia moderna en España (1900-1950) de Manuel Pulido Mendoza (Mérida: Editora Regional de Extremadura/Universidad de Extremadura, 2009); y la Tesis doctoral de Francisco Soguero Garcia titulada "La renovación del género biográfico en España '1929-1936': Estudio de las biografías vanguardistas de César Muñoz Arconada, Benjamín Jamés y Antonio Espina" (Bilbao, Universidad de Deusto, 2005). El biografismo que surgió en España desde fines de los años veinte del siglo $X X$ procedente de Europa, especialmente de Francia, Alemania e Inglaterra, y que por los mismos años se expandió por Hispanoamérica, fue un 
consideración de biografia literaria o moderna para la Vida novelada de Pedro Blanco permite también subrayar las reflexiones que sobre el asunto desarrolló el mismo Novás y que lo conectan directamente con las aportadas por los principales promotores de la renovación del relato de vidas 4 . A partir de su integración en el estallido editorial biográfico que se produjo en España e Hispanoamérica a fines de la segunda década del siglo $X X$, las relaciones entre historia y ficción identificadas en El negrero se explican por la tradicional pugna de fuerzas entre el archivo y la invención característica de la biografía, que alcanza su grado máximo en el modelo de entreguerras, surgido bajo la irónica originalidad de los textos de Lytton Strachey y el impulso novelesco y popular de las obras de André Maurois ${ }^{5}$. La historicidad y la literariedad de estos modernos relatos de vida dan cuenta del pulso entre la vindicación de un irrenunciable rango artístico dignificante del biografo y los límites de elasticidad permitidos por la realidad documental al afán creador. Para Novás la verdad del ser humano debe captarse en la intuición del carácter del sujeto y del espiritu de su época; según él mismo enuncia, los hechos a falta de

fenomeno editorial de vasto alcance y efímera duración. Durante esta época se produjo una profunda revisión de los fundamentos compositivos en la redacción de vidas humanas, que dio paso a una concepción más artística de la misma. El texto se hizo más literario, se orientó hacia la verdadera captación del interior del sujeto, se huyó del panegirico y se privilegió la personal y libre mirada interpretativa del biografo en el uso exhaustivo del archivo. De ese modo la taxativa prohibición de inventar hechos se diluyó en una nueva definición del documento, según la cual este perdía su rigidez en favor de posibilidades más fecundas dictadas por el deseo de profundizar en un alma concebida como misterio a descifrar. Teoria y práctica no siempre confluyeron, y son numerosas las dificultades a la hora de determinar la separación entre la arbitrariedad ficcional y la recreación intuitiva (abierta a la audacia del biógrafo) de los acontecimientos registrados.

- A partir de algunos de sus artículos, cartas, entrevistas y prólogos es posible construir una consistente (aunque no muy desarrollada) teoría biográfica de Novás y afirmar que su práctica en este terreno no se da aisladamente ni se limita a $E l$ negrero, sino que presenta ramificaciones de mayor alcance en su escritura, fundamentalmente como periodista y articulista a lo largo de su estancia en España
entre 1931 y 1939.

5 Concretamente las obras que en general se consideran iniciadoras y fundamentadoras de este biografismo son Eminent Victorians (1918) de Lytton
Strachey y Aspects de la biographie (1928) de André Maurois. 
aportes documentales pueden ser de modo restringido inventados, siempre que lo ficticio sea un medio para realzar la esencia vital e historica del biografiado: "Nadie ha podido hacer aún la biografía de un pirata sin cubrir vastas lagunas con puentes conjeturales de imaginación. Esto no merece reparo, siempre que la imaginación no falsee, sino que ponga de relieve, la esencia, el carácter del personaje y del medio en que actu $6^{\prime \prime} 6$. Vida y novela, pues, se concilian en esta muestra de fusión del archivo y el mito consagrado al oficio crepuscular del negrero, cuya figura genérica es romanceada a partir del paradigmático Pedro Blanco. La recreación literaria del archivo descansa aquí sobre la original perspectiva con que el periplo del protagonista es sesgado por un halo de legendario romanticismo y sobre una pluralidad de recursos artísticos pertenecientes a un estilo narrativo en pleno proceso de configuración que el autor exhibirá en simultáneas y futuras composiciones ${ }^{7}$.

Desde el mismo subtítulo, Novás explicó su obra como vida novelada. Vida o biografía por abarcar la totalidad de una existencia, desde el nacimiento hasta la muerte, y porque los principales personajes y acontecimientos que estructuran la narración son fidedignos. Novelada porque los vacíos informativos se completan con hechos verosímiles y probables, ofrecidos por el acopio documental ${ }^{8}$. La consulta de

"Novás Calvo 1936105.
7 Las relaciones de El negrero con algunas de las producciones cuentísticas de Novás
son evidentes, no solo en lo estilistico, sino también respecto al tema desarrollado.
Las más significativas son las que se establecen entre "El otro cayo", "Aquella
noche salieron los muertos", "Long Island", pertenecientes a su libro de relatos La
luna nona y otros cuentos (1942), y "Cayo Canas" recogido en Cayo Canas (1946).
Además los dos primeros aparecieron en 1932 en Revista de Occidente, aunque "El
otro cayo" con un título ligeramente distinto "En el cayo".
Otras reconstrucciones biográficas o literarias del tratante malagueño lo
presentarán de modo diferente: Gerardo González de Vega en Mar brava: historias de
corsarios, piratas y negreros españoles (1999) prescinde del exacerbado armazón
romántico y recoge la etapa cubana tras su retiro como mongo en África para
anotar sus frustrados intentos por introducir a su hija en la aristocracia criolla.
Antonio Altadil en su folletín Barcelona y sus misterios (1969) lo presenta de modo
maniqueo como paradigma del villano cobarde incapaz de hacer frente a las
virtudes morales y a la audacia del joven protagonista.
8 Décadas después en una entrevista Novás abundo en el carácter heterogéneo de
su obra: "Es novela y es biografía porque los hechos principales, los puntos de 
obras históricas, sociologicas, antropológicas le proporcionan un rico cauce para la recreación de una época y una institución que retrata a partir de la figura de Blanco. Así, la base documental alusiva a su protagonista, se complementa con la referida al contexto y a otros personajes reales que compartieron su terrible oficio y con los que efectivamente convivió. Con frecuencia y de forma explícita los hechos de Blanco se identifican como actos iterativos de un sistema comercial y un modo de vida verificados por el relato oral de los marineros. A la vez esas relaciones funcionan como proyección de las anécdotas históricas acopiadas por Novás en la labor previa a la escritura. En ese sentido, la propia naturaleza legendaria de la figura biografiada, la calidad pseudo-histórica de algunas de las principales fuentes (como los diarios de negreros) y la perspectiva adoptada por el autor hacen que las dosis de ficcionalización sean evidentes; sin embargo, ello no puede ocultar que un gran número de los pasajes que recrean la existencia del mongo de Gallinas provienen de la concreción artística de una base histórica.

El estudio de la historicidad y de la literariedad del texto permite establecer el alcance que en las dos direcciones puede descubrirse en El negrero ${ }^{9}$. La carga hipotextual, paratextual e intertextual pone de manifiesto la vinculación con el biografismo de entreguerras y naturaliza las características de unos elementos que han sido calificados a menudo como extraños e incluso falaces ${ }^{10}$. Entre los elementos más

apoyo, son verdaderos, ese personaje existió. Pero después hay lagunas llenadas con la suposición, con la imaginación, con los hechos posibles, verosímiles, probables, pero que sería muy difícil comprobarlos en detalles" (Gutiérrez de la Solana 71; citado por Espinosa Domínguez 46).

${ }^{9}$ Las posibles desviaciones que la reconstrucción realizada por Novás de la vida de Blanco presenta con respecto a sus fuentes históricas han sido analizadas por Luis (1990) y Walker (2005).

${ }^{10}$ Gérard Genette en su obra Palimpsestos. La literatura en segundo grado, establece una taxonomía, dividida en cinco categorías, de lo que denomina "transtextualidad o transcendencia textual del texto": intertextualidad, paratextualidad, metatextualidad, hipertextualidad y architextualidad. Para Genette la intertextualidad es "la relación de copresencia entre dos o más textos [...], la presencia efectiva de un texto en otro", y puede manifestarse de tres formas: la más convencional es la cita entrecomillada seguida o no de la referencia explícita, después se añadirían de modo menos marcado y en distintos grados de literariedad, el plagio y la alusión. En cuanto a la 
destacados de tales mecanismos transtextuales cabe señalar la bibliografia y cronología finales sobre la esclavitud y la trata, las notas a pie de página, la reproducción del interior de la bodega de un barco negrero como descripción del modo en que los esclavos eran hacinados en él, un epígrafe, los diarios del negrero Theodore Canot y el militar John Gabriel Stedman y el estudio Los negros esclavos (1916) de Fernando Ortiz. Los argumentos literarios además de insistir en su pertenencia a este modelo de vidas, conectan la obra con la producción global de Novás, en cuyo seno deja de verse como un hecho aislado. También es importante sostener que ni siquiera la condición de "obra de encargo" aísla la creación de unos intereses personales que ya se habían manifestado en reflexiones teóricas cercanas a los nuevos pos-

paratextualidad, la define como "la relación [que] el texto propiamente dicho mantiene con [...] su paratexto: título, subtítulo, intertítulos, prefacios, epílogos, advertencias, prólogos, etc.; notas al margen, a pie de página, finales; epígrafes; ilustraciones; fajas, sobrecubierta, y muchos otros tipos de señales accesorias, autógrafas o alógrafas, que procuran un entorno (variable) al texto". Un tercer modo señalado por el crítico es la metatextualidad, que califica como "la relación crítica" por antonomasia, es decir, "la relación -generalmente denominada "comentario" - que une un texto a otro texto que habla de él sin citarlo (convocarlo), e incluso, en el límite, sin nombrarlo". Por otro lado, la hipertextualidad (a la que dedica el grueso de esta obra) es entendida como la vinculación entre un texto B o hipertexto y un texto A o hipotexto que le precede y del cual se deriva bien por transformación o por imitación (transformación indirecta). Finalmente, un quinto tipo de relación transtextual es la architextualidad, considerada como "el conjunto de categorías generales o transcendentes -tipos de discurso, modos de enunciación, géneros literarios, etc.- del que depende cada texto singular" (Genette 9-22). Cfr. Martinez Fernández (2001).

José M. Fernández Pequeño ha rechazado radicalmente la raigambre histórica, de manera que el aparato erudito de la bibliografia, el apéndice de fechas sobre la trata y las notas a pie de página, es decir, los diversos elementos paratextuales han sido contemplados como una serie de "trampas tendidas por Novás Calvo" (Fernández Pequeño 10). Desde esta línea interpretativa, la esencia primordial vendría dada por la poderosa vertiente fabuladora e imaginaria desplegada por encima de los cauces históricos y del pretexto biográfico inicial. Igualmente Jorge Febles ha sido tajante en la defensa de esta visión al advertir sobre la necesidad de considerar dichos elementos pseudo-históricos como meros controles de verosimilitud, que no deben llevar a una "errónea e ingenua lectura historicista" (Febles 760), puesto que "toda esa información y todo ese afán bibliográfico del que Novás hace ostentación es un engaño para reinventar desde la perspectiva de la fantasía al personaje y la circunstancia histórica en que este se mueve" (Fernández Pequeño 10). 
tulados biográficos y que se repitieron en posteriores artículos sobre el asunto, $\mathrm{e}$ incluso en la planificación de otras recreaciones de personajes de la historia. En suma y más allá de la indefinición nominal que ha afectado a $E l$ negrero, es innegable que la obra sobre el tratante español forma parte del biografismo de la época y que los abundantes elementos ficcionales se entretejen con amplias referencias documentales en un texto de alta densidad artística.

Dentro del espacio dedicado al análisis de la transtextualidad en $E l$ negrero, cabe hablar de la presencia que en la obra cobran los discursos hegemónicos planteados por Roberto González Echevarría en su obra Mito y archioo (2000) como hipotextos reconocibles en las que considera obras clave de la historia de la narrativa latinoamericana ${ }^{11}$. Según postula este crítico, el rasgo común que presentarían tales obras sería paradójicamente el afán por encubrir o rechazar su naturaleza literaria, alojando su escritura en el seno de una estructura y un lenguaje perteneciente al discurso de poder predominante en el momento de su composición, respecto del cual, en un nuevo giro, tendería a evadirse o diferenciarse: "la característica más persistente de los libros que han recibido el nombre de novelas en la era moderna es que siempre han pretendido no ser literatura. El anhelo de no ser literaria, de romper con las belles-lettres, es el elemento más tenaz de la novela" (González Echevarría 30$)^{12}$. Las sucesivas retóricas discursivas por medio de las

\footnotetext{
"En esta obra, el autor señala como hitos cruciales en la evolución de la narrativa latinoamericana los Comentarios reales del Inca Garcilaso de la Vega, Facundo de Domingo Faustino Sarmiento, Os sertões de Euclides Da Cunha y entre otras más contemporáneas, Cien años de soledad de Gabriel García Márquez. A partir de ahora las citas tomadas de esta obra se señalarán directamente en el texto con el nombre del autor y el número de página.

${ }^{12}$ En el seno de su argumentación, González Echevarría asevera que "el proceso de simulación y fuga de formas impuestas por el poder que subyace en todas estas narrativas es la fábula maestra de la novela" (10). Asimismo, preconiza que al carecer de un contorno exclusivo singularizador, "la novela generalmente asume la de un documento dado, al que se le ha otorgado la capacidad de vehicular la 'verdad' -es decir, el poder- en momentos determinados de la historia", de tal modo que la novela se integra en "la totalidad discursiva de una época dada, y se sitúa en el campo opuesto a su núcleo de poder. La concepción misma de la novela resulta ser un relato sobre el escape de la autoridad, relato que generalmente aparece como una especie de subargumento en muchas novelas" (Id. 32).
} 
cuales la novela latinoamericana, según González Echevarria, habría tratado de legitimar la verdad transmitida en sus textos, se convierten de este modo en el aspecto caracterizador y determinante de una evolución que se extendería desde la presencia subtextual del lenguaje legal en las producciones de la época colonial, hasta llegar a la presencia mediadora de la ciencia, primero en forma de los textos de los naturalistas y viajeros europeos en el siglo XIX, y después a principios del siglo XX, a través del corpus antropológico, que trataba de identificar los mitos, culturas y lenguajes determinadores de la singularidad y diferencia de Latino América. González Echevarría sostiene que "la novela se derivó del discurso legal del imperio español durante el siglo XVI" y que tanto la picaresca, que "constituye la primera simulación novelesca de la autoridad textual", como las primeras relaciones del proceso de descubrimiento y conquista de las Indias Occidentales, "imitan -simulan- el lenguaje de la autoridad encarnada en el discurso de la ley, cuyo depósito y símbolo es el archivo de Simancas" (González Echevarría 9). Un segundo periodo, que abarcaría desde fines del siglo XVIII hasta la segunda década del XX, vendría establecido por la preponderancia del modelo científico decimonónico, expresado bajo la forma del diario de viaje de hombres de ciencia como Von Humboldt y Darwin, que contribuyeron a través de una exhaustiva recopilación de datos sobre la realidad natural y social americana a su nominación y catalogación, labor que los convertiría en los nuevos cronistas y descubridores del Nuevo Mundo (González Echevarría 36). A partir de 1920, el autor de Mito y archivo establece un tercer periodo fundamentado a través de la presencia hipotextual en la "novela de la tierra" de un nuevo tipo de modelo proveniente del ámbito de las ciencias, "el informe antropológico o etnográfico" (González Echevarría 38), marcado por el análisis del lenguaje y los mitos fundadores de las sociedades objeto de estudio, o por la imagen que de sí mismas tenían estas sociedades, es decir, el conocimiento que poseían sobre ellas:

El conocimiento antropológico proporcionó a la narrativa latinoamericana una fuente de relatos, así como una fábula maestra sobre la historia latinoamericana. En la ficción, la historia latinoamericana se moldeará ahora en forma de mito, una forma derivada de los estudios antropológicos (González Echevarría 208-209). 
Ya Roberto Véguez da cuenta de esta relación entre la teoría propuesta por González Echevarría y el texto de Novás, cuya hibridez esencial, a su juicio, haría difícil la inclusión de este último en una categoría genérica concreta, situándolo "entre ficción e 'historia"”; de tal manera, que los postulados echevarríanos ofrecen un nuevo marco teórico que permitiría una original perspectiva en su análisis y contribuiría a "revalorizar su importante contribución al desarrollo de la narrativa latinoamericana"13. Para este crítico existe una correspondencia entre los tres momentos evolutivos determinados por el autor de Mito y Archivo y la estructura tripartita de la obra sobre Blanco. El primer libro, sobre la infancia de Pedro, se relacionaría con la picaresca y la hegemonía del documento legal; el segundo, con la narrativa de viajes científicos, en los que el discurso de la ciencia proporcionaría la legitimidad ansiada por la literatura; y el tercero, parece que lo identifica con el discurso antropologico. En este sentido, Véguez afirma que El negrero "reúne entre sus tapas un esquema del desarrollo histórico de la novelística latinoamericana hasta ese momento y que al tratar de ir más allá se anticipa a la nueva narrativa latinoamericana del llamado 'boom'", puesto que anuncia la última etapa apuntada por González Echevarría: "la ficción del Archivo", aunque sea en "una parte que normalmente se consideraría extra-textual, en la bibliografía"14.

A pesar de lo establecido por Véguez, probablemente no sea tan sencillo determinar una relación demasiado estricta entre el esquema evolutivo echevarríano y los límites de la estructura ternaria de esta biografía. En primer lugar, como señala el mismo Véguez, la narración en primera persona, uno de los principales elementos de la retórica picaresca, está ausente y la similitud con esta debe basarse en otros rasgos como el origen humilde y la orfandad del protagonista, la fama ambigua de la madre y el arquetipo del padrastro, o la figura estricta del dómine al que acaba enfrentándose de un modo u otro. Se trataría pues, más de una coincidencia en ambientes y situaciones marginales que en la presencia del carácter jurídico textual que González Echevarría observa en las obras con las que ejemplifica su postura, y que

${ }^{13}$ Véguez 43.

${ }^{14}$ Id. 54 .

Futhark 9 (2014)

ISSN 1886-9300

Gomez de Tejada, Hipertextualidad, 121-152 
remiten "más técnicamente al modelo real del texto picaresco: la deposición o confesión de un delincuente dirigida a alguien investido de autoridad" (González Echevarría 15). Incluso la irregular aparición de un yo discursivo en la narración de la infancia de Pedro aludida por Véguez, está claramente alejada del motivo picaresco, y es evidente que no se corresponde con la voz del personaje principal, sino con un testigo indefinido. Además, tales situaciones marginales se prolongan a lo largo del libro, por ejemplo en la segunda parte, en las asociaciones de Blanco con simples e incompetentes rateros, promotores de pequeños hurtos que fracasan de modo estrepitoso: el asalto a la posada de María Cruz o a la hacienda de Modesta Pedrão; o también, en los ambientes portuarios donde marinos sin barco iban en prueba de uno a otro "como perros", por ejemplo, en Cádiz, que "ya no era rica, pero aún abundaba el pícaro formado por los mentidos tesoros de América"15. El submundo marginal propio del género tiene su referencia amplia en los espacios donde los despojos del mar y de la trata se hacinan en grupos caracterizados por la promiscuidad o la miseria, fundamentalmente los marineros parias que Pedro encuentra en las fondas de todos los puertos por los que pasa y a los que más tarde recogerá en su propia factoría, o también las prostitutas de nacionalidades tan diversas como las de los hombres de mar, del mismo modo encalladas en las ciudades portuarias. A estos resabios picarescos se ha añadido a veces su identificación genérica con el bildungsroman. Sobre ello hay que apuntar que tal denominación a pesar de que ha sido a menudo empleada para etiquetar aquellas narraciones que abarcan el periodo de formación del protagonista entre la adolescencia y la madurez, su uso más allá de un periodo determinado de la literatura alemana no está exento de polémica. De todos modos, si se parte de las características señaladas por aquellos que han adoptado una postura integradora cabe decir que junto a las coincidencias se presentan diferencias irreconciliables: la narración de la completa existencia del protagonista desde su nacimiento hasta su deceso y la

15 Novás Calvo 1999 37. A partir de ahora las referencias a esta obra se anotarán simplemente indicando el número de página en el texto. 
ausencia de tono irónico que subraya la distancia entre héroe y narra. dor ${ }^{16}$.

Igualmente en la tercera parte, el motivo de la "carta de relación" como modelo legal de la creación literaria tomará forma anecdótica en la obra al utilizar el mongo Blanco los mecanismos administrativos imperiales para denunciar la intrusión de los ingleses en la colonia espanola Fernando Poo por medio de un aviso a las autoridades gubernamentales españolas y del encargo a un socio de porfiar en el envío de cartas regulares, donde tratase en su nombre de las ventajosas condiciones estratégicas de la isla y dejase constancia de su patriotismo. Con este acto, se reproduce la función otorgada a las confesiones de pícaros y a los testimonios de los cronistas de América, en las que la adopción de las formulas burocráticas del poder "era una manera de garantizar la legitimidad del autor y de dar crédito a su relato" (González Echevarría 93) ${ }^{17}$; con él, las epístolas del capitán, negrero y mongo Pedro Blanco, y las del factor Burón se insertan en la corriente de documentos legales situada en el otro extremo de la oralidad con que había forjado su mitificación en el mar y en la costa africana, desde la que su promotor a través de la imitación del discurso oficial pretende el reconocimiento de unos méritos que le otorgarían libertad, emancipación y estatus en el propio seno del Estado ${ }^{18}$ :

${ }^{16} \mathrm{Cfr}$. Femández Vázquez 51-61.

Un ejemplo de la aplicación de este vocablo puede encontrarse en Luis que asevera que “Novas Calvo's Bildungsroman follows closely Blanco's biography, from his mischievous childhood to his life as a slave trader and pirate. Blanco's apprenticeship on board slave ships culminates with him turning Gallinas into one of the most important factories supplying slaves to the New World" (Luis 163). Daroqui ha apuntado a su inclusión en los "bildungsromans caribeños" (197), y Febles ha aseverado que se da una perspectiva global de la trata por medio del "esquema estructural característico del bildungsroman" (759).

17 "Escribir era una manera de conseguir la libertad, la legitimación. El pícaro, el cronista y, en cierto sentido, todo el Nuevo Mundo, buscaban obtener la concesión de derechos y una validación de su existencia escribiendo sus relatos" (González Echevarría 77).

18 "El simulacro del poder reemplaza el poder mismo a fin de anularlo. Colón, Cortés, Bernal y Garcilaso entablan sus propios alegatos, precarios y a menudo cuestionados, de su estado civil y político valiéndose del discurso legal" (González Echevarria 97). 
En Pedro se desperto, como accidentalmente, una refinada ambición. Su carrera de marino había sido frustrada por unos sentimientos morales, contra los cuales se había desarrollado su vida. ¡Qué interesante, si aliora lograba un alto honor de la Armada con el mismo tiro que partía un ala al enemigo que se oponía a la continuación de aquella vida! (270)

Respecto de la parte intermedia y de mayor extensión de El negrero, en que se narran las peripecias de Blanco desde su huida de Málaga hasta su asentamiento en Gallinas, y sus relaciones con el segundo momento historiográfico teorizado por González Echevarría, Véguez señala que este libro "se adentra en el mundo anti-heroico y episódico del pícaro, pero en proporciones impensadas por Lazarillo", y añade que "el discurso hegemónico es el de los libros de viaje de observadores y científicos europeos decimonónicos" 19 . El texto modelo de esta etapa es Facundo, de Domingo Faustino Sarmiento. Realmente la reducción de las peripecias del protagonista a los estrechos márgenes de la picaresca se ve dificultada por las dimensiones de marginalidad y rebeldía que el negrero va adquiriendo en su fuga y en su afán de autoconocimiento, además de por los vínculos que su caracterización permite establecer con los diferentes prototipos señalados por Rafael Argullol para el héroe romántico: "el nómada", "el genio demoníaco", "el suicida" (fundamentalmente en las escenas simbólicas que sumergen a Blanco en atmósferas ultraterrenas), "el enamorado", "el superhombre" y "el sonámbulo"20. A lo largo del texto su identificación con la mayoría de los atributos del malditismo heroico asociado a los más relevantes personajes míticos de este movimiento, va dejando muy atrás esas primeras vinculaciones con la identidad del pícaro y su cosmovisión. De hecho, la explicitación del carácter romántico del personaje central es señalada por el propio narrador y sublimada en el paralelo trazado con una de las figuras románticas por antonomasia, Napoleón Bonaparte, que es utilizado en la configuración estructural y espiritual de su vida:

Había muchos barcos en el puerto y el zoco estaba lleno de marineros borrachos, revolcados entre las familias de mercaderes, los encantadores de serpientes y los mendigos. Todos los ladrones y truhanes vaga-

19 Véguez 47.

${ }^{20}$ Argullol 371-430. 
han por el zoco viejo. A veces pasaban espanoles con capa y judios de banca. De Londres, París y Barcelona iban rameras que se alojaban en tugurios de judios. A veces se las compraba por prendas, y se iban a dar a los barcos. Realmente, aquélla era una gran lección para un romántico como era Pedro (34-35).

La conexión que Véguez apunta con el Facundo es, precisamente, la utilización del mito napoleónico en ambas obras. Para González Echevarría en el texto de Sarmiento el emperador francés supone "una de las referencias más frecuentes" (González Echevarría 145), ya que este hecho remarca la vinculación del segundo periodo de la obra con el discurso hegemónico de los diarios de viaje de científicos y aventureros del XIX. No obstante, hay que tener presente que las apariciones napoleónicas son recurrentes a lo largo de El negrero -"Una cábala de fechas había enlazado sus viajes con los del emperador, y la noticia de su muerte en el momento en que se disponía a quedarse en África debió de tocar lo que en él hubiese de superstición" (201) - y que la búsqueda del conocimiento, así como su descripción y clasificación a través de la retórica naturalista del ochocientos cobra significación considerable también en el capítulo final, donde este tipo de intereses se entrecruzan con otros de índole antropológica y etnográfica. En gran medida, en las dos últimas partes del libro la voz del narrador y la acción de Pedro Blanco vienen determinadas por el estudio de diferentes realidades sociales y naturales, y por el análisis de elementos culturales tales como el lenguaje y el mito. El dibujo de las sociedades portuarias y marinas adquiere a nivel diegético un estilo taxonómico y descriptivo de reminiscencia científica, por ejemplo, en torno a "los hombres de Cojimanco":

Su mercancía se dividía en tres clases: primera, segunda y tercera, que él llamaba trinquete, mayor y mesana. La de trinquete era escasa y costaba cara. Se componía de tigres de mar, hombres desesperados y sin alma, que sólo servían para piratas. Los hombres de mayor eran los que servian para barcos medio negreros y medio piratas, los que iban a comprar negros y no tenían escrúpulos en robarlos a otros cuando la ocasión se presentaba favorable. Los de mesana sólo servían para negreros honrados (195).

E igual ocurre en las visiones ofrecidas sobre los grupos de ñañigos cubanos, de la vida en los ingenios azucareros, los criaderos de 
esclavos, las factorías y las tribus africanas, que se intercalan entre los viajes realizados por Blanco, pero también en el relato de la creación de su imperio negrero, que se enriquece con la aportación de innumerables datos sobre la geografía, el clima, la naturaleza y los habitantes de la zona:

El estuario de Gallinas era una fuente de esclavos desde 1813, pero los factores españoles y portugueses caídos allí eran de una madera blanda y su comercio irregular. Los negreros no tocaban allí sino cuando no podian entrar en las costas de Oro y de los Esclavos, la inseguridad de encontrar cargamento y la carestía de los esclavos eran dos dificultades. Los factores dependían de las guerras feudales de las tribus interiores y a veces llegaban caravanas de prisioneros y no tenían con qué comprarlos. Estas caravanas estaban formadas por negros emigrantes de la región de Vey, que habían avanzado desde el sur, fundiéndose en parte con los gallinas establecidos en clanes aislados en los diferentes brazos del río. Al norte estaban los bullón -mampúas-, también en clanes rivales, y los gallinas formaban expediciones contra ellos o iban a comprar sus prisioneros de guerra. La selva tenía veredas, especie de túneles que sólo penetraban las caravanas a pie que partían al norte y al sur de las márgenes de los ríos, especialmente el Cestos, el Gallinas y el Sulima.

Los cayos del estuario de Gallinas estaban poblados especialmente por la "raza" de pescadores. Había tres clases de gentes: los krumen crewmen, tripulantes, boteros-, procedentes de la Costa de los Granos y desparramados por toda la costa; los fishmen -pescadores- $\mathrm{y}$ los bushmen -silvestres-, que cazaban y cultivaban tierra adentro. Los silvestres mediaban entre los factores y los jefes del interior y los boteros entre los factores y los negreros. Los pescadores eran buenos para los trabajos de las factorías (202).

En el fragmento anterior se puede observar la conjunción de objetivos comerciales, científicos y aventureros como propulsores de los viajes de los científicos europeos durante el siglo XIX, así como un recuerdo de la valoración funcional que Colón realizaba en sus diarios de los habitantes del mundo recién descubierto ${ }^{21}$. De manera recurren-

21 González Echevarría asevera que "las modernas potencias imperiales, por intermedio de instituciones encargadas de adquirir y organizar el conocimiento [...] comisionan a individuos con competencia científica para viajar a sus colonias o a colonias posibles para recopilar información [...]. La ecuación entre poder y 
te se alude a la distintiva calidad intelectual del protagonista, capaz de recitar textos de memoria en latín, conocedor de diferentes lenguas europeas y africanas, su instrucción náutica y, en definitiva, su com. pulsivo deseo de saber, que le llevaba "a estudiar el idioma del país y a indagar los nombres de las tribus cercanas -Mende, Gora, Bussi, Kpwesi, Gibi, Sikong- , sus territorios, supersticiones, feudos y organización" (206), siempre con un sentido práctico, dirigido al afianzamiento y expansión de su poder y fama. Según se desprende de la narración, el prurito antropológico y naturalista de Pedro Blanco tenía una aplicación directa a su actividad negrera y constituía una fuente primordial de su capacidad de control sobre marineros e indígenas, si bien la mitología del mar, fundamentalmente la alusiva a aspectos del más allá y diversas fantasmagorías, atenazaba su espíritu hasta el estremecimiento:

Cada vez que se presentaba alguien procedente de un lugar lejano, Pedro lo hospedaba y lo convidaba a champán. La geografía lo obsesionaba, y su factoría era una caja de resonancia de la historia de Europa y América, al través de los cuentos de los marineros, que ahora caían allí como langostas, venidos de Sierra Leona. Por ellos supo de la expedición del capitán Owen, y a bordo de su barco mandó secretamente un marinero ingles para que le informara de los detalles del reconocimiento (232).

Del mismo modo puede considerarse como parte de esta conexión hipotextual con el poder legitimador del discurso naturalista, la irrupción de la tecnología europea en el litoral africano, favorecida por la actitud emprendedora e imaginativa del capitán Blanco, cuyas estrategias de potenciación del negocio negrero a través de ingenios desconocidos para los nativos son paralelas al conjunto de instrumentos con los que científicos europeos se aproximaban al estudio de la realidad americana:

Pedro aprovechó esta estación para construir veinte puestos de vigilancia a lo largo de la costa, sobre árboles y torres de ladrillos, consiguiendo que los demás factores contribuyeran a sostener en ellos vi-

conocimiento, entre colección y posesión no podía ser más patente, en particular si consideramos que muchos de los viajeros [...], eran representantes de empresas que participaban en algún tipo de explotación económica" (149-150). 
glas provistos de telescopios [...]. Al mismo tiempo transmitio a los armadores un código de señales heliográficas y por medio de fogatas, para orientar a los negreros en la costa. Pedro había encargado a Alemania una docena de aparatos con espejo y telescopio, que enviaban los rayos del sol a muchas millas de distancia. En África nadie había usado aquellos aparatos [...]. Los vigías no confundían jamás un crucero con un negrero, y así sabían cuándo enviar las señales. Los pestañeos de los espejos tenían todo un alfabeto: si había negros, si había cruceros, si éstos estaban al llegar, si había tiempo de cargar, a qué hora podian hacerlo, de donde era el negrero a quien iba consignado, qué mercancías llevaba, qué mercancías escaseaban, qué precio tenían los esclavos. Era el principio del sistema de vigilancia más perfecto que había tenido la costa. Pedro adquirió el nombre de Mago-Espejo-Sol (223-224).

Se puede apreciar, por tanto, cómo las convenciones de las dos áreas científicas mencionadas como hitos evolutivos sucesivos de la historia de la novela latinoamericana aparecen simultáneamente en los libros segundo y tercero de El negrero, donde la profundización en las mitologías propias y ajenas se presenta de igual modo y paralelamente al proceso de mitificación y automitificación del biografiado. $\mathrm{Si}$ durante su estancia en Gallinas la imagen de Pedro entre los tribales se va señalando a partir de las denominaciones que por sus actos estos le asignan; a lo largo de sus viajes de puerto en puerto y de barco en barco, la voz narrativa da cuenta de cómo su figura se va invistiendo de un aura legendaria e indescifrable desde sus inicios de grumete hasta su consagración como temible negrero y pirata. En ambos periodos de su vida, Pedro Blanco contribuirá consciente y teatralmente a inspirar en el otro la sumisión a su irresistible aureola mítica:

Mientras los marineros se distraían por la noche, las figuras de los oficiales cruzaban de un lado a otro como sombras teatrales, como empeñados en grandes planes, con son marcial, por donde les daba la luna. Los marineros los veían y sus figuras se quedaban en ellos. Esto ocurre así. Pedro sabía que la disciplina consistía en grabar la imagen de un hombre sobre la que otro tiene de sí. Luego queda allí grabada y el 
subordinado no se puede ver si no es al través de la imagen del otro $(182)^{22}$

Finalmente, también apunta Véguez como "punto de contacto con la ficción de archivo", la adición al final de una lista de "Obras especialmente útiles para el estudio de la trata y la esclavitud de los ne. gros" a modo de bibliografía base de esta vida novelada de Pedro Blanco. En su articulo reduce a este elemento paratextual el anuncio en ella del último periodo de la narrativa latinoamericana analizado por González Echevarría, aunque en realidad su condición de precedente pueda atisbarse en otros muchos y más esenciales aspectos diegéticos de la obra de Novás. De forma genérica y sin que ello lleve a una forzada correspondencia letra por letra, en El negrero pueden ser reconocidos los tres elementos que este crítico designa como identificativos de las más determinantes muestras de la novela contemporánea, de la cual Los pasos perdidos de Alejo Carpentier sería el punto de partida, Cien años de soledad de Gabriel García Márquez el ejemplo arquetípico, y Terra Nostra de Carlos Fuentes su materialización más abarcadora (González Echevarría 54). Para González Echevarría, el concepto de "Archivo" como eje vertebrador de la escritura e interpretación de las obras fundamentales de la novela de Latinoamérica durante parte del último tercio del $X X$, se define a partir de tres ejes reiterados en sus relatos:

1) La presencia no sólo de la historia, sino de los elementos mediadores previos a través de los cuales se narró, ya sean documentos jurídicos de la época colonial o científicos del siglo XIX; 2) la existencia de un historiador interno que lee los textos, los interpreta y los escribe; $y$, por

\footnotetext{
${ }^{2}$ La presencia en las dos partes de El negrero del procedimiento de auto-creación de su propia leyenda se puede percibir con claridad en la repetición parcial de esas palabras en el libro tercero: "En aquellos meses nadie sabía dónde encontrarlo. De golpe se presentaba en casa de un jefe, hacía brillar las armas ante sus ojos y desaparecía. Era un modo de sorprender a las gentes, grabando en ellas su imagen y envolviéndose en un misterio donde trabajaran la superstición y la imaginación" (213). E igualmente en estas otras donde se subraya la doble naturaleza de la leyenda de Pedro y su influjo sobre ambos grupos étnico-sociales: "Lo primero era dejarles ver posibilidad de botín, después de imprimir en cada uno su propia estampa de capitán, cerrada, dura y misteriosa. Gran parte era natural en él, no efecto buscado; pero él no perdonaba tampoco ningún recurso, fuera el que fuera, para sacar partido así de blancos como de negros" (215).
} 
altimo, 3) la presencia de un manuscrito inconcluso que el historiador interno trata de completar (González Echevarría 50).

También añade la constatación de un espacio físico que adquiere la funcion emblemática del Archivo como área para el registro del "conocimiento clasificado y almacenado por el Estado", como recinto o prisión de documentos legitimados por la relación entre la literatura y el poder, o más sencillamente, como lugar de depósito de textos claves para el desciframiento del secreto mítico y los orígenes de una sociedad y su cultura, o de su versión reducida representada por una genealogía familiar (González Echevarría 128).

En El negrero, en un sentido amplio y evitando el encorsetamiento que significaría pretender una superposición exacta de la obra de Novás respecto de las premisas sugeridas por González Echevarría, pueden leerse dichos rasgos, aunque signados en gran medida por la propuesta de oralidad que recorre el impulso de la obra. La vida e intereses de Pedro Blanco tal y como aparecen recogidos se orientan en un doble sentido comunicativo, polarizado en el empleo placentero y reivindicativo de la oralidad y el uso práctico y subversivo de la escritura (aunque a veces tales prácticas se entrecrucen, de modo que lo escrito adquiera presencia en el ámbito amoroso y familiar a través del intercambio epistolar, y la búsqueda de auto-mitificación conlleve el impulso sesgado de la transmisión oral de la fama). Como texto de origen biográfico, el peso de lo histórico es axial en este relato, las alusiones al proceso de descomposición de la trata, en cuyo seno gira la vida del protagonista, son abundantes a lo largo de sus páginas y llegan a convertirse en un elemento condicionante de la acción y generador de tensión. Las fuerzas abolicionistas británicas se ciernen coercitivamente sobre el negocio esclavista en general y sobre el Estado levantado en Gallinas por Pedro Blanco en particular. La etapa crepuscular del sistema negrero es paradójicamente su edad de oro (como afirman algunos protagonistas) y en sus límites cronológicos el capitán Blanco alcanza un éxito y una fama desmedida, sin embargo eso no impedirá, como así lo percibe él mismo, el lento final irremediable de la secular estructura económica y comercial sobre la cual se 
habian sostenido hasta entonces las culturas y los imperios europeos occidentales $^{23}$.

El paralelismo que se establece entre la figura del autor, Lino Novás Calvo, como biógrafo de Pedro Blanco, y de este como biógrafo de Napoleón Bonaparte, se corresponde también con el que se produce, esta vez con el mismo objeto de estudio, entre creador y personaje en su afán por conocer el mundo de la trata. La diferencia fundamental entre ambos procesos se halla en el método de análisis, puesto que si Novás recurre necesariamente al Archivo escrito como única fuente posible de información, Pedro Blanco elegirá la entrevista ( $y$, claro está, la observación) como vías de recogida de datos para construir lo que en gran medida se propuso y consiguió Novás: un romancero del comercio de esclavos, sobre todo de las aventuras experimentadas en alta mar por los negreros: "Lo que me propongo no es hacer historia propiamente, ni menos de tierra -sino novela de mar, que valga por intensa antes que por extensa... Unas cuantas escenas de la trata con Blanco por centro, algo de antología con unidad sin salirme del personaje ni del tema concreto: la trata, el cómo se hacía"24. El Archivo sobre la trata que supone la escritura de El negrero, es el reflejo escrito de la construcción de otro Archivo de carácter oral, romancesco, que Pedro Blanco guarda en su memoria a través del filtro que su sensibilidad fabuladora e hiperestésica supone para los relatos míticos que en puertos, factorías y barcos escucha en boca de múltiples navegantes igualmente traspasados por una cosmovisión mágica de la experiencia marítima y negrera. Si tal impulso se debe en el personaje a su carácter desmedidamente aventurero y fabulador que rechaza, desde su marginalidad, el poder oficial de la letra escrita para otorgar a la palabra oral una función subversora de la versión institucionalizada a través de su configuración como discurso henchido de plenitud mágica, delirante y viva, en el literato, por el contrario, se debe a las carencias documentales de un Archivo que pese a su vastedad es esencial-

\footnotetext{
${ }^{23}$ Daniel P. Mannix afirma que, tras la ilegalización global y progresiva de la trata por imposición de los ingleses a principios del siglo XIX, durante toda la primera mitad del mismo el contrabando de esclavos no se extinguió, sino que aumentó, de manera que "Cuba por sí sola constituía un mercado casi tan grande como lo fuera anteriormente todo el hemisferio" (Mannix; Cowley 190).

${ }^{24}$ Novás Calvo 56.
} 
mente incapaz de contenerlo todo, y que conduce al bibgrafo a cumplimentar los huecos a través de paralelismos y fusiones de distintas experiencias vitales, que tiñen la narración de las peripecias de Blanco de un tono de generalidad, fundamentalmente perceptible en el Libro II, que adquiere matices etnográficos y sociales. Así, Novás muestra a su personaje de modo semejante a como ciertas obras contemporáneas incluyen en su seno la figura del manuscrito, del archivista o erudito y del mismo Archivo, es decir, en su personaje hay un deseo por reconstruir narrativa y objetivamente la historia, pero haciéndolo desde dentro, desde el mismo acontecer de los hechos, de cuyo epicentro se encuentran subjetivamente lejos las reelaboraciones oficiales de los núcleos de poder:

Era esto en 1814. Resonaban aún los ecos de los cañones de Soult, y de los balcones caían coplas contra los franceses. Pero eso no tenía sentido para el pirata que había en Pedro. Lo que él buscaba era la narración objetiva de los hechos de aquel gran hombre llamado Napoleone. Y esto no podía encontrarlo. Narrar y objetivamente no lo sabía hacer nadie entonces. Todos se sentían sujetos y líricos (37).

Por ello, Martínez y Blanco se ríen y desmienten internamente las peripecias terribles narradas por el sordo Lippman, cuyos relatos provienen de una fuente escrita, que convierte la experiencia en un discurso mediatizado por la subjetividad y la lírica de la época, esterilizando la riqueza y la verdad de la transmisión oral y directa, desde dentro de la vida y de los acontecimientos que ansía el propio negrero protagonista. Puede que no sea exagerado considerar la sordera del marinero inglés Lippman como símbolo de su incapacidad como elemento receptor y transmisor ubicado dentro del circuito de oralidad que fundamenta la experiencia y cosmovisión marinera, para quedar inserto de modo antitético en el de la literatura escrita. Frente a la clásica figura del rapsoda ciego, eternizada en Homero como epítome del discurso oral, este personaje secundario se erigiría de modo paródico como representante del texto gráfico como forma de transmisión.

La biografía de Blanco, y por ende el devenir histórico del comercio de esclavos, recibe un tratamiento acorde con esta perspectiva de análisis que subraya la conversión de la historia en mito fundacional 
dentro de las páginas de la narrativa latinoamericana moderna ${ }^{25} \mathrm{Al}$. berto Garrandés en su prólogo a la segunda edición cubana de la obra apunta que "las rutas de su negrero [el de Novas] nos hacen penetrar en la dimensión mítica de la aventura del conocimiento, visitar una estancia en la cual la historia se traduce al lenguaje cosmopolita de multitudes que se suman inconscientemente al secular proceso de creación del rostro y el cuerpo del Nuevo Mundo" 26 . El primer libro, a través de un lenguaje a menudo bíblico y mítico, presenta reminiscencias con el paraíso del principio de la creación. El incesto de los personajes remite al pecado original de la cosmogonía cristiana, según la cual la humanidad procedería de la unión de los primeros humanos, él creado por Dios a partir del barro, ella creada a partir de la carne de este. Existía pues un parentesco carnal entre ambos seres protegidos por la ingenuidad primigenia de su naturaleza, sin embargo el conocimiento en forma de manzana y de serpiente somete su existencia común a la coerción del pecado. Igualmente, Pedro y Rosa disfrutan su carnalidad como una prolongación de sus juegos infantiles y juveniles, como refugio de su soledad interior y reducto ante la hostilidad exterior. Como Adán y Eva, el conocimiento supondrá la expulsión del paraíso. La confirmación del pecado les llega primero bajo la amenaza del infiemo impuesta por el cura que adoctrina a Pedro en la moral católica y le revela el estigma indeleble que le acompañará siempre. Después a modo de castigo popular inspirado en las Sagradas Escrituras que condenaban a los culpables de esta aberración sexual a lapidación pública. Pedro huirá y comenzarán su periplo en el mar y la tormenta de su alma, Rosa se quedará sometida a la ignominia y a la afrenta de un pueblo incapaz de perdonar. Ninguno de ellos, separados o vueltos a reunir, recuperará jamás el paraíso original.

\footnotetext{
${ }^{2}$ Una interpretación de tonalidad mútica y religiosa sobre la actuación de España en sus colonias, respecto a la política esclavista y misionera allí desarrollada, es vertida por el narrador implícito a través de las palabras del piloto de un navío negrero, que augura un final apocalíptico y sangriento para los españoles -blancosa manos de negros e indios: "Los negros -dijo el piloto- llevaban la selva consigo a América y eso estaba bien. Yo me alegro; España ha querido crear almas sin cuerpo en América y les ha sembrado el camino de carbones negros y espinas indias, y eso se prenderá en llamas, y ya se ha prendido, y las almas lo serán en pena" (127).

${ }^{26}$ Garrandés 33.
} 
Segán González Echevarría, en Cien años de soledad el mito está presente a través de relatos y personajes semejantes a los incluidos en las Sagradas Escrituras o en las leyendas clásicas, narraciones con elementos míticos entre los que destaca el inicio incestuoso o violento presente en la mayor parte de las cosmogonías (González Echevarría 46). La interpretación que en este sentido aplica a la obra garciamarquina puede extenderse en gran medida a El negrero, que abandona a menudo los lineamientos históricos de la biografía para adentrarse en el ámbito mitológico y romancesco de la narración legendaria. La narración de la "vida novelada" de Pedro Blanco se constituye como un relato donde se hibridan artísticamente aspectos característicos de la biografía, la historia y el mito, cuya fusión a menudo da lugar a una retórica basada en la reiteración y en la generalización que permite la captación del ambiente vertido en los moldes de un posible romancero de la trata.

Otro aspecto fundamental dentro de esta línea argumentativa es la creación de una sociedad en el seno de la selva, el elemento fundacional que liga la novela con parte de la temática de las crónicas del descubrimiento y la conquista, así como con los discursos de la pobreza y la abundancia ${ }^{27}$. En este sentido, la huida de la factoría del mongo John y sus primeras experiencias al mando de una pequeña nave negrera lleva a Blanco casi a través de un naufragio, o al menos de una navegación repleta de obstáculos y calamidades (conatos de motín y

\footnotetext{
${ }^{27}$ Pastor (2008) analiza entre otras la escritura de Cristóbal Colón, Hernán Cortés y Alvar Núñez Cabeza de Vaca como un proceso en que el testimonio ofrecido se transforma de la palabra mitificadora sobre la realidad americana y la figura del conquistador de los dos primeros a otra caracterizada en el último por la desmitificación de esa naturaleza y el fracaso de la empresa de exploración y conquista; desarrollo que en gran medida puede asociarse a la experiencia de los nuevos territorios como espacios hiperbólicos de la abundancia y la pobreza, que en El negrero coexisten habitualmente en la costa africana. Por su parte, al referirse a ciertos rasgos de la descripción que autores como Colón, Bernal Diaz del Castillo y especialmente, en su argumentación, el Inca Garcilaso de la Vega dentro de sus Comentarios Reales, Julio Ortega señala que "el discurso sobre el Nuevo Mundo será un discurso de la abundancia", al tomar como horizonte narrativo "el modelo [... de] la abundancia, la noción de la fecundidad y la riqueza" (Ortega 42, 45). Sin embargo, nuevamente en relación al Inca el mismo Ortega afirma que este "no dejará de referir el modelo antagónico, el de la carencia" (Id. 12).
} 
enfermedad a bordo), a un precario desembarco en la costa de Gallinas, donde el mísero nivel de negocio y la austera conducta de los factores europeos que alli se encuentran, suponen un contraste evidente con el fructuoso comercio, los delirios de poder y disoluta actitud que aglutinaban las factorías y personalidades de Cha-Cha Da Souza y John Ormond. Como descubridores precedentes, el ingenio de Blanco registra la nueva realidad desde una perspectiva comercial, filtrando los elementos de la naturaleza y los habitantes del lugar a través del tamiz del negocio esclavista: la desembocadura del río facilita el embarque, las islas constituyen lugares estratégicos para la construcción y defensa de barracones, almacenes y viviendas que integran las dependencias de todo centro de recepción y venta de esclavos en el litoral africano, las costumbres y el estado social de los indigenas se prestan de modo idóneo a la acción corruptora potenciadora de la trata. Aunque lo pospone, Pedro Blanco ya ha decidido dónde levantará su imperio negrero y la precaria sociedad que en tomo a él habrá de articularse. Tras su regreso a Gallinas sienta las bases del nuevo estado, en un proceso que se construye sobre el envilecimiento y la desintegración de las sociedades anteriores, cuyos integrantes son cosificados y transformados en mano de obra esclava, al mismo tiempo que sus relaciones familiares y sociales y sus recursos militares, legales y religiosos son conscientemente viciados por los intereses comerciales de una civilización occidental representada por el biografiado. Sin embargo, la devastación de las sociedades autóctonas implica el crecimiento del incipiente país fundado por el tratante malagueño, que le proporcionará una identidad formal, espiritual y jerárquica obtenida de su experiencia en el mar: los edificios de su factoría tienen la forma de un barco, la organización responde a grados y funciones marineras, y, por último, la fuerza para su creación, consolidación y mantenimiento se destila del hálito intrépido y aventurero fraguado en la navegación.

Además, Blanco consolida dicha vertiente fundacional a través de su capacidad para reinventar los mecanismos del grupo socioeconómico en el que se ha insertado, es decir, el gremio de los negreros. Ante la presión que el movimiento antiesclavista ejerce sobre los tratantes y, en general, sobre los dispositivos del comercio de esclavos, su imaginación fabulosa combinada con un innovador sentido prácti- 
co elabora nuevos procedimientos para reactivar el negocio. Entre tales creaciones patenta un lenguaje de signos lumínicos que complementa un riguroso sistema de vigilancia con el que consigue burlar el acoso abolicionista. Así, en la novela (y en su vida real) Blanco opone su lengua de signos a la palabra escrita y oficialista, su código de luces a los pasquines legalistas que el imperio británico reparte por África. Ello además se suma a la cultura, a priori y en general, ágrafa de los marinos, esencialmente oral y legendaria, subsumida por el transporte de esclavos o de productos relacionados con tal actividad, que invierte y desviste de autoridad el discurso hegemónico del poder de múltiples maneras hasta llegar a la parodia: en las formas de contratación de los marinos, cuya leyenda contada por ellos mismos o por otros navegantes en el espacio periférico del puerto o en el interior de alguna de sus fondas (verdaderos ámbitos de resistencia frente a la historia oficial) se convierte en el mejor aval para su admisión a bordo, de modo que quedan desdeñados los documentos escritos -hoja de servicios, certificados legales-, también la utilización de uniformes, pabellones, pinturas y nombres de los barcos como medio para la realización de fines piráticos, el empleo fraudulento y corrupto de los mecanismos legales para burlar los tratados de restricción de la trata referidos a compra de barcos, transporte de mercancías, puertos de salida y destino; en la perspectiva aventurera que invierte el sentido de la acción abolicionista y transforma el periodo de ilegalización de la trata en una auténtica "edad de oro" para el tráfico negrero; en la caricaturización que surge al sustituir la grafía oficial del nombre de uno de los principales responsables del movimiento abolicionista inglés, Wilberforce (como aclara el propio narrador entre guiones), por su trascripción fonética oficiosa, "Bílifor" (127), según la pronuncian los marineros, que consigue oponer jocosamente lo oral-marginal a lo escrito-nuclear ${ }^{28} ; y$, sobre todo, en la comentada utilización que el propio Pedro Blanco hace en su "única estratagema internacional" de los procedimientos diplomáticos e instituciones gubernamentales al

${ }^{28}$ A continuación, entre desmedidas risas, el piloto de un negrero vierte en estilo directo su visión de las octavillas abolicionistas repartidas por los cruceros ingleses en "la bahía de São Paulo": "-Este señor Bílifor -Wilberforce- querría que los negreros gobernaran a estas panteras con guante de terciopelo, ¿eh? Yo le daria esta armazón para transportar a América a ese inglés -dijo el piloto" (127). 
denunciar la invasión britanica de Fernando Poo, territorio insular español junto a la costa noroccidental de Africa, y que le supone la fugaz obtención de un nombramiento como "intendente de la Arma. da":

Segun los tratados, de los cuales Pedro estaba al tanto, Fernando Poo era española, y Pedro paso un aviso firmado al Ministerio de Ultramar, denunciando la intrusion. Si los ingleses tenían que abandonar la isla, el peligro de Gallinas y sus sucursales sería menor. Un negrero de Cádiz que logró cargar a principios de estación llevó el pliego sellado por el senor de Gallinas, la única estratagema internacional que había empleado. Sus espejos, vigías y lugares no bastaban en la lucha contra la represion. Cuando él abandonara Gallinas, toda estrategia sería insuficiente. Burón quedo encargado, al mismo tiempo, de insistir en la denuncia, subrayando en nuevas cartas al ministro de Ultramar el servicio que Pedro había querido prestar a la patria y lo que Fernando Poo podia significar, por su posición estratégica, para España (269).

Tal recurso remite a las prácticas de la escritura de la literatura colonial hispánica, que utilizaba los canales legales de la crónica y la epístola para reivindicar los derechos alcanzados a través del descubrimiento y la conquista, es decir, para legitimar ante la corona sus pretensiones nobiliarias, territoriales y económicas. Igualmente utiliza Blanco junto a los recursos orales de la rumorología y la fama diseminada por todos los puertos por marinos hipnotizados por sus dotes y leyenda y por otros convenientemente estimulados, un importante aparato epistolar destinado a la invención y propagación de un nuevo territorio mítico caracterizado como espacio promisorio para el negocio esclavista:

En esta segunda estación sólo tocaron allí negreros de Cuba y el Brasil; pero desde Freetown llegaron cartas de armadores de Liverpool, Bristol, Nantes, Burdeos, Cádiz, Lisboa, Charleston y Baltimore, anunciando que en la próxima mandarian expediciones a Gallinas. Todas aquellas cartas iban dirigidas personalmente a Pedro. Él había pagado a varios marineros para que difundieran la fama de su factoría, abultando su importancia. Los armadores quedaban así cogidos en una tenaza, que formaba la leyenda de los marineros y las circulares de Martínez (218). 
Por otro lado, a diferencia de la creación del lenguaje jurídico y escrito que suele acompañar a la constitución de ciudades y estados, el texto de Novás no incluye dicho recurso y, como en el mar y en el gobierno del barco, construye su aparato represivo y punitivo a partir de la autoconsciente mitificación de su propia figura, cuya imagen mitologica pretende grabar en las impresionables mentalidades de los aborígenes africanos, del mismo modo que anteriormente lo había hecho sobre la de los marineros a su mando ${ }^{29}$. Como ya quedó comentado, las fases de dicho proceso legendario van siendo marcadas por las denominaciones que las tribus acuñan para designarlo: "Ahorcado" (221), "Gran Mago" (224), "Mago-Espejo-Sol" (224), "FuegoBarco" (251); y también las que establecen los blancos: "señor de Gallinas" (230), "mongo" (257); o incluso, el propio narrador, "dictador" (257). Refuerza de este modo, la perspectiva oral que la novela tiene en el nivel del contenido y en el de los recursos técnicos, y que se ve nuevamente incrementada porque Blanco, a pesar de todo construirá su propio lenguaje, cuya subversión se origina en su carácter no escrito y en ser empleado como un instrumento de lucha frente a la coerción hegemónica británica.

Pedro Blanco, como en cierto sentido el protagonista-narrador de Los pasos perdidos, ejerce las veces de descubridor y conquistador, de naturalista y antropólogo (musicólogo). En el primer caso, puesto que la desembocadura de Gallinas a pesar de que llevaba tiempo siendo explotada como puerto esclavista, la dispersión, incapacidad e indolencia de los factores europeos allí asentados y el escaso aprovechamiento de los recursos que sólo la visionaria mente de Blanco alcanza a vislumbrar, confiere categoría de descubrimiento a su llegada a esta zona del litoral africano; a la par que el progresivo afianzamiento de su poder y leyenda, que desemboca en la constitución de un nuevo estado con su propia bandera, adquiere valor de conquista. Por otra parte, la explicitación del interés de Blanco hacia la lengua, las cos-

29 "Pedro se dedicó a visitar los jefes de tribus río arriba, tratando de deslumbrarlos o atemorizarlos, siempre con una escolta personal de tres o cuatro marineros. En aquellos meses nadie sabía nunca dónde encontrarlo. De golpe se presentaba en casa de un jefe, hacía brillar las armas antes sus ojos. Era un modo de sorprender a las gentes, grabando en ellas su imagen y envolviéndose en un misterio donde trabajaran la superstición y la imaginación" (213). 
tumbres sociales, los usos religiosos y mitologicos, $y$ las instituciones políticas tribales del estuario de Gallinas, lo asemejan a la figura de los antropologos y naturalistas europeos que recorrieron otros continentes durante el siglo XIX guiados por el afán taxonómico y científico de la época. El conocimiento de estos aspectos es usado por Blanco, sin embargo, para la manipulación de la mentalidad indigena en su propio beneficio y para articular su propio mito por medio de hechos que le dotan de un aura sobrenatural de gran ascendencia sobre los indígenas, puesto que, como afirma el narrador revelando la mentalidad del protagonista, "a África se la podía conquistar por medio de los sentidos, el miedo o la religion" (213). Múltiples conductas y acciones pergeñadas por Blanco se dirigen a mantener su fama y su reputación frente a los negros de las tribus que le suministran esclavos, pero también ante sus propios marineros y factores asociados: la muerte del portugués que se comió a la bruja, el incendio del barco de María Cruz, la invención del lenguaje de espejos, el mantenimiento del harén.

Desde esta perspectiva puede reconocerse en el protagonista la figura homodiegética caracterizada por un impulso historicista fundamentado en la recopilación, interpretación y escritura de los textos, que González Echevarría postulaba como segundo elemento axial del tipo de obras incluidas en la ficción del Archivo. La situacion marginal del investigador, la esencialidad aventurera de su devenir, el fin eminentemente práctico de su estudio y la naturaleza oral de la tradición marinera impiden la plasmación de los resultados por escrito; $s i n$ embargo, de modo recurrente la voz narradora informa al lector del prurito biográfico de Blanco en torno a la figura del emperador francés y de su frustrada tentativa de reconstruir su imagen desde dentro, debido a la índole subjetiva de la información recibida, a partir de la cual el entrevistado hablaba más de sí mismo que del sujeto en cuestión. De esta dificultad, en gran medida insalvable puesto que viene determinada por el ambiente romántico y lírico de la época, se percibe la presencia de un relato oral -en lugar de manuscrito- inconcluso, que remitiría a ese tercer elemento propuesto por González Echevarría. 
Finalmente, el espacio archivístico que podría identificarse con el recinto para la custodia de manuscritos adquiere dentro del clima general de oralidad y degradación, un carácter heterogéneo, conversacional y viciado que convierte las más truculentas tabernas portuarias, las más corruptas factorías y el más infecto hospital en centro de documentación fidedigna y extraoficial sobre el universo de la trata. Entre tales lugares, la trastienda de la posada de don Justo en La Habana aparece como paradigma de local de asociación entre la marinería, refugio frente a la autoridad y "caja de resonancia de todas las cosas de La Habana y de aun algunas fuera de ella", verbigracia, el "Tratado de abolición con Inglaterra", cuyos parámetros son refutados categoricamente por los tertulianos de la parroquia, que oponen su propia verdad y objetivos a los propósitos antiesclavistas ingleses. Las perspectivas antitéticas de los discursos del poder y de la periferia, palabra escrita frente a palabra oral, son subrayadas al suministrar la narración las fechas históricas y los términos incluidos en los convenios entre los distintos países, recogiendo a continuación el rumor popular no escrito. De esta manera, el libro de Novás se convierte en gran medida en un archivo de la otra historia, de una realidad marginada por la autoridad institucional, respecto de la cual supone una fuga y un elemento más de la tensión entre historia y ficción propia de los textos biográficos: "-¿Abolición? -dijo un piloto negrero-. Abolición. ¡Mentira! Seguiremos acarreando negros hasta que no quepa uno más en la isla. Los meteremos por todos los costados y los pagarán bien y todos ganaremos. ¡Ja, ja!" (116). Este recinto permite incluso la aparición de una escritura que se percibe como precaria, promiscua, casi carnavalesca, a veces cronística o lírica, siempre vulgar y subversora de aquella otra asociada a las jerarquías dirigentes y administrativas:

En la trastienda, los marineros quejosos de algún barco aguardaban ocasión de denunciar las atrocidades del capitán y otros oficiales para que nadie se enrolara en él. Los patriotas pegaban a la pared décimas contra la metrópoli o el capitán general y anunciaban hecatombes. Las mujeres que entraban allí escribían en las mesas las señas de sus accesorias. Se anunciaba la venida de algún decimero o guitarrista del interior, algún garganta de oro de Italia, la venta de algún esclavo, una lidia de gallos en Guanabacoa, y se entablaban polémicas sobre religión 
y gramática. Todo lo que pasaba y no pasaba, pero que se chismeaba, iha alli a hacerse letras $y$ palabras con vino, y los marineros iban a leerlo. A veres se veian desafíos y retos a cuchillo sobre un adverbio o una declinación [...] pero ahora las letras más grandes anunciaban cuidado contra el carnaval de los negros, que se celebraría dentro de unos días, dia de Reyes (117).

En último término, hasta el pequeño ataúd en forma de nave donde Blanco transporta los restos de su hermana, puede verse como el pequeño archivo donde se contiene la clave de su carrera pirática y negrera, enigmática personalidad y paradójica fortuna; interpretación que resulta de dificil acceso, puesto que los propios personajes, representados por los loqueros, leen mal los signos de su espíritu y descodifican en sentido económico un corazón eminentemente romántico. A partir de ella, el lector puede encontrarse con el prisma desde el que el autor trata de responder a la pregunta formulada por algunos contemporáneos a Theodore Canot, y que él mismo confesó no saber precisar:

Se me ha preguntado frecuentemente qué clase de carácter mental puede ser el de quien, voluntariamente, se aísla casi toda la vida en medio de pestilentes pantanos, en un clima quemante, traficando con came humana, provocando guerras, sobornando y corrompiendo a negros ignorantes, siempre fuera de la sociedad, sin diversiones, alegrias o cambios, sin amigos, fuera de los hombres, en guerra contra las leyes, con todos sus vínculos rotos, excepto los creados por la avaricia entre los descastados europeos que voluntariamente se hacen satélites de hombres tales como don Pedro. Invariablemente les he respondido que este enigma africano me ponía tan perplejo como a las personas de orden y vida normal, las que, por cierto, se encontraban muy asombradas ante los gustos y la larga carrera de un factor de esclavos alejado en los pantanos de Gallinas ${ }^{30}$.

Como más tarde el origen de Macondo en Cien años de soledad, la fundación del imperio comercial de Blanco hunde sus raíces en la repetición de los orígenes mitológicos, en las interdictas relaciones entre hermanos, en la huida exigida por una sociedad y en la búsqueda de un nuevo paraíso sustitutivo del original ya irremediablemente perdido.

${ }^{30}$ Canot 156-157. El subrayado es mío. 
En definitiva y como ya hiciese Véguez, es posible incluir El negrero en la categoría de ficciones del Archivo, cuarto tipo de la tipología latinoamericana y que compondría para la historia de la narrativa zada por la utilización del renovado esquema moderna. Singularide la explosión de popularidad alcanzada biográfico, que a tenor Hispanoamérica puede leerse, en alguna medida época en Europa e ridad latente bajo la escritura novelesca (gracia, como texto de autoximidad que la biografía ha mantenido (gracias a la relación de prosar de la tensión entre realidad y ficción la verdad histórica, a pediferenciada por la constitución de un Archivícita en su práctica); oral y transitorio, almacenado de manera ivo predominantemente populares en las que resuenan los ecos mara inestable en "bibliotecas" cador al cual los anónimos protagonistas de la del rumor recodifiversión oficial; cronológicamente anterior a la historia someten la dos, Cien años de soledad y Terra Nostra- a las obras -Los pasos perdirrollo de dicha fase, la Vida novelada denaladas como hitos del desase constituye en precedente legítimo dedro Blanco Fernández de Trava dón a la reivindicación de su importancias mismas y añade tal galarpanoamericano.

\section{REFERENCIAS BIBLIOGRÁFICAS}

AlTADIL, Antonio, Barcelona y sus misterios, Barcelona, Taber, 1969.

ARGULLOL, Rafael, El héroe y el único. El espíritu trágico del romanticismo, Barcelona, Destinolibro, 1990.

CANOT, Theodore, Memorias de un tratante de esclavos, Buenos Aires, Centro Editor de América Latina, 1976.

DAROQUI, María Julia, "Escribir el sujeto anómalo. [Des]Leer El Negrero de

Novás Calvo", Revista Iberoamericana, 67 (2001), págs. 191-200.

ESPINOSA DOMÍNGUEZ, Carlos, Entre la provincia y el mundo: modernidad e innovación en la narrativa de Lino Novás Calvo, Ph.D. Supervisor Florence Yudin, Miami, Florida Internacional University/UMI, Ann Arbor, 2004.

FEBLES, Jorge, "La ineludible voz tácita del otro en El negrero: vida novelada de Pedro Blanco Fernández de Trava", Hispania, 84: 4 (2001), págs. 758-766.

FERNÁNDEZ PEQUEÑo, José M., "Lino Novás Calvo: del desarraigo a la paradoja", en Novás CAlvo, Lino, 8 narraciones policiales, Santiago de Cuba, Oriente, 1995. 
FERNÁNDEZ VAZQUEZ, José Santiago. La nozcla de formación. Una aproximación n la ideologia colonial curopea desde la óptica del Bildungsroman clásico, Madrid, Servicio de Publicaciones de la Universidad de Alcala, 2002.

GARRANDÉs, Alberto, "Lino Novás Calvo y la identidad literaria hispanoamenicana", en Novas CALvo, Lino, Pedro Blanco el negrero. La Habana, Letras Cubanas, 1997, págs. 5-33.

GENETTE, Gérard, Palimpsestos. La literatura en segundo grado, trad. Celia Fernández Prieto, [1982] Madrid, Taurus, 1989.

GONZALEZ DE VEGA, Gerardo, Mar braza: historias de corsarios, piratas y negreros españoles, Barcelona, Ediciones B, 1999.

GONZALEZ ECHEVARRIA, Roberto, Mito y archivo: una tcoría de la narrativa latinoamericana, trad. Virginia Aguirre Muñoz, México, Fondo de Cultura Economica, 2000.

GutiérRez de la SOl.ANA, Alberto, "Lino Novás Calvo: Literatura y Experiencia", Caribe, primavera (1977), págs. 61-75.

Lofez Campillo, Evelyne, La Reoista de Occidente y la formación de minorías, Madrid, Taurus, 1972.

Luts, William, "Historical Fictions: Displacement and Change -Lino Novás Calvo's El negrero and Alejo Carpentier's The Kingdom of This World", en Luts, William, Literany Bondage: Slazery in Cuban Narrative, Austin, Texas, University of Texas Press, 1990, págs. 162-198.

ManNIX, Daniel P.; Cowley, Malcom, Historia de la trata de negros, trad. Eduardo Bolívar Rodríguez, [1962] Madrid, Alianza, 1968.

MARTINEZ FERNÁNDEZ, José Enrique, La intertextualidad literaria, Madrid, Cátedra, 2001.

Novás Calvo, Lino, Laberinto de fuego. Epistolario de Lino Novás Calvo, La Habana, La Memoria, Centro Cultural Pablo de la Torriente Brau, 2008.

-. "El Olonés, hermano de la costa"', Revista de Occidente, 52: 154, abril-junio (1936), págs. 101-115.

- El negrero. Vida novelada de Pedro Blanco Fernández de Trava, Barcelona, Tusquets, 1999.

ORTEGA, Julio, El discurso de la abundancia, Caracas, Venezuela, Monte Ávila, 1992

PASTOR, Beatriz, El segundo descubrimiento. La Conquista de América narrada por sus coetáneos '1492-1589', [1983] Barcelona, Edhasa, 2008.

ROMERO, Cira, Fragmentos de interior. Lino Novás Calvo: su voz entre otras voces, Santiago de Cuba, Oriente, 2010.

VÉGUEZ, Roberto, "Pedro Blanco, el negrero: ¿novela o biografía novelada?", Simposium, 54: 1 (2000), págs. 43-56.

WALKER, D. J., "History and Fiction in The Slave Trader: The Novelized Life of Pedro Blanco Fernández de Trava by Lino Novás Calvo", Wadabagei, 8: 2 (2005), págs. 72-102. 